\title{
Structural, electrical and thermodynamical aspects of hydrogenated La-Ni-Si alloy
}

\author{
ANKUR JAIN, R K JAIN, SHIVANI AGARWAL and I P JAIN* \\ Material Science Laboratory, Centre for Non-Conventional Energy Resources, 14, Vigyan Bhawan, \\ University of Rajasthan, Jaipur 302 004, India
}

MS received 18 May 2005; revised 29 December 2005

\begin{abstract}
The structural, electrical and thermodynamic properties of a $\mathrm{La}-\mathrm{Ni}-\mathrm{Si}[\mathrm{La}=28.9 \%, \mathrm{Ni}=67.5 \%, \mathrm{Si}=$ 3.6\%] alloy have been investigated. Powder XRD results show that the lattice constants and unit cell volume of the alloy increase after hydrogen storage. It was also found that the resistance of the alloy increased with dissolved hydrogen concentration. Hydrogen absorption pressure composition isotherms have also been investigated which show the presence of two single $\alpha$ and $\beta$ regions and one mixed $(\alpha+\beta)$ phase. The thermodynamic parameters viz. the relative partial molar enthalpy $(\Delta H)$ and relative partial molar entropy $(\Delta S)$ of dissolved hydrogen, are found to be in the range 8-18 $\mathrm{kJ}(\mathrm{mol} \mathrm{H})^{-1}$ and $25-63 \mathrm{JK}^{-1}\left(\mathrm{~mol} \mathrm{H}^{-1}\right.$. From the dependence of $\Delta H$ on the hydrogen concentration, $X$, the different phases $[\alpha, \alpha+\beta, \beta]$ and phase boundaries of the alloy$H$ system are identified. Thermal conductivity and diffusivity of La-Ni-Si and its hydride have been measured at room temperature by using TPS technique. Thermal conductivity was found to decrease due to absorbed hydrogen in the alloy.
\end{abstract}

Keywords. PCT isotherms; hydrogen storage materials; TPS; thermodynamics; thermal properties; electrical properties.

\section{Introduction}

Hydrogen, the most abundant element in the universe, has great potential as an energy source. It is non-polluting and forms water as a harmless byproduct during use. Yet it is so difficult to store that its use as a fuel has been limited. It has been well established that hydrogen reacts directly and reversibly with many metals and alloys to form metallic hydrides. Metal hydrides have generated considerable interest in the last 30 years for safe and easy hydrogen storage. Metals and alloys intended to serve as hydrogen storage media must provide the hydriding/dehydriding procedure to occur at a hydrogen partial pressure as close as possible to atmospheric pressure. The particle size, phase composition, hydriding capacity and other properties of that metal or alloy should be unchanged after a number of absorption/ desorption cycles. Although recent progress in metal hydrides has been significant, it has to be admitted that there has not been any real progress in efforts to advance the room temperature hydrogen storage capacity of traditional hydrides. Different categories of compounds have been studied such as $\mathrm{LaNi}_{5}, \mathrm{MgNi}_{2}$, TiFe, $\mathrm{ZrFe}_{2}$ (Schlapbach et al 1988, 1992; Yamaguchi and Akiba 1994; Wipf 1997). Recently, single walled carbon nanotubes and sodium alanates related hy-

*Author for correspondence (ipjain46@sify.com; ankurjainankur@sify.com) drides have also attracted attention as promising materials for hydrogen storage (Bououdina and Guo 2000).

Among these, La based material is considered as a promising material for hydrogen storage because of its high hydrogen storage capacity, favourable hydrogen absorption/ desorption characteristics and formation of hydride at convenient temperature (Ahn and Lee 1991; Josephy et al 1991; Hector et al 2003; Devi Babita et al 2004). Schlapbach $(1988,1992)$ observed segregation of metallic nickel particles at the surface of $\mathrm{LaNi}_{5}$ hydride and held that they play an active role in hydriding process by catalyzing the dissociative chemisorptions of hydrogen.

The study in which Ni is replaced has been done recently by many workers. Seo et al (2003) reported that the addition of $\mathrm{V}$ and $\mathrm{Zr}$ causes improvements in the discharge capacity and cyclability of $\mathrm{AB}_{5}$ type alloy with multicomponent system. Nakamura et al (2004) studied the strain formation and lattice parameter change in $\mathrm{LaNi}_{4.75} \mathrm{Sn}_{0.25}-\mathrm{H}$ system and found that significant changes occurred in hydride phase both in the single phase and two-phase regions only in dehydriding but not in hydriding state. They also deduced that the behaviour of $\mathrm{LaNi}_{4.75} \mathrm{Sn}_{0.25}$ in lattice parameter change and lattice strain formation during hydriding/ dehydriding is quite different from those observed in $\mathrm{LaNi}_{5}$ but is similar to those seen in $\mathrm{LaNi}_{4 \cdot 75} \mathrm{Al}_{0 \cdot 25}$. Besides these, some other pseudo-binary compounds have also been reported for some elements like Mn (Notten and Latroche 
1999) and $\mathrm{Cu}$ (Latroche et al 1999). Sato and Yartys (2004) measured P-C-T isotherm volumetrically at temperatures between 258 and $453 \mathrm{~K}$ and calculated the partial molar enthalpy and entropy for $\mathrm{LaNi}_{5} \mathrm{Sn}-\mathrm{H}$ system. Some other recent investigations of the thermodynamic properties of hydrogen absorption in various systems are by Jacob and Berznitsky (2002), Berznitsky and Jacob (2003) and Sivakumar et al (2000). Many efforts have been made to estimate the thermal conductivity $(\lambda)$ and thermal diffusivity $(\chi)$, but simultaneous measurement of the above has not been made so far. The TPS technique (Gustaffson 1991) made it possible.

In the present work, we are presenting the relationship between the hydrogen concentration and resistance of the alloy. The hydrogen absorption characteristics have been investigated in the range $0.50 \geq P \geq 10$ bar and $30 \geq T \quad 60^{\circ} \mathrm{C}$. Also the enthalpy and entropy of system have been calculated using Vant' Hoff plot. The measurement of thermal conductivity, thermal diffusivity and specific heat of the material and its hydride have not been carried out at room temperature using transient plane source (TPS) technique.

\section{Experimental}

\subsection{Material characterization}

The alloy was supplied by the Defence Metallurgical Research Laboratory (DMRL), Hyderabad. The alloy was well characterized by DMRL for its homogeneity. We also characterized the material using XRD to determine the lattice parameter and cell volume. The X-ray diffraction patterns were obtained by means of a standard PW 1840 powder diffractometer, operated at $40 \mathrm{kV}$ and $25 \mathrm{~mA}$, and equipped with a scintillation counter with single channel pulse height discriminator associated counting circuitry. The FeK $\alpha$ radiation, $\lambda=1.93604 \AA$, was collimated with soller slits. The X-ray diffraction patterns were collected in a step-scanning mode with $\Delta 2 \theta=0.02$ steps and then transferred to a PC for processing. The XRD patterns were analysed using the PowderX and Treor Programme for calculation of crystal structure and lattice parameter.

\section{$2.2 P-C-T$ isotherm measurement}

To study $\mathrm{P}-\mathrm{C}-\mathrm{T}$ isotherms the data were collected using an experimental set up based on water displacement method developed in our laboratory (Jain et al 2002). To study in situ resistance with change in hydrogen pressure, a modified reactor vessel was used for containing the material having an electrode with ceramic insulation. $10 \mathrm{~g}$ of alloy was kept in the reactor vessel, which also had a provision for heating and for measuring temperature and hydrogen pressure. Prior to an absorption run the whole system was evacuated to $1 \times 10^{-3}$ torr and the sample was degassed at $473 \mathrm{~K}$ for $1 \mathrm{~h}$, exposed to hydrogen and then slowly cooled to room temperature. The sample was again degassed. In this way a virgin surface was produced for hydrogen storage. After each experiment the sample was degassed at $473 \mathrm{~K}$ under a vacuum of $1 \times 10^{-3}$ torr.

\subsection{Transient plane source technique}

The transient plane source (TPS) is a portable thermal probe with the ability to measure simultaneously thermal conductivity and thermal diffusivity from cryogenic temperature to $1000 \mathrm{~K}$. It can take solids, powders or liquids having thermal conductivity between $0.02 \mathrm{~W} / \mathrm{mk}$ and $200 \mathrm{~W} / \mathrm{mk}$. The TPS method consists of an electrically conducting pattern in the form of bifilar spiral, which also serves as a sensor for temperature increase in the sample. It is made of $10 \mu \mathrm{m}$ thick nickel foil with an insulated $50 \mu \mathrm{m}$ thick layer of kapton, on each side of the metal pattern. Each TPS element had a resistance of about $3.26 \Omega$ at room temperature and a TCR of around $4.6 \times 10^{-3} \mathrm{~K}^{-1}$ owing to the change in average temperature of the sensor; the potential difference across the terminal and the current through the TPS sensor is recorded by digital power supply. The current in the circuit is adjusted according to the nature of the sample material. The TPS programme used here is capable of recording the temperature of the sample through the TPS itself. The whole arrangement is described elsewhere (Singh et al 2002).

\section{Results and discussion}

\subsection{Structure of alloy}

$\mathrm{La}_{28.9} \mathrm{Ni}_{67.5} \mathrm{Si}_{3.6}$ crystallizes in the orthorhombic structure (space group, $P$ ) as confirmed from the powder $\mathrm{X}$-ray diffraction patterns taken at room temperature with $\mathrm{FeK}_{\text {a }}$ radiation (figure 1). The changes in unit cell parameters are very small. It can be seen that the diffraction pattern for the hydrides is identical to that of the parent alloy except for the increase in unit cell volume. The lattice parameters of the alloy are given in table 1.

\subsection{Activation of alloy}

Figure 2(a) gives a plot of hydrogen pressure with time during the first few activation cycles. In the beginning the material absorbs hydrogen slowly, indicating the presence

Table 1. The unit cell constants and volume of $\mathrm{La}-\mathrm{Ni}-\mathrm{Si}$ alloy.

\begin{tabular}{lrrrc}
\hline System & $a(\AA)$ & $b(\AA)$ & $c(\AA)$ & $V(\AA)^{3}$ \\
\hline $\mathrm{La}_{28.9} \mathrm{Ni}_{67.5} \mathrm{Si}_{3.6}$ & 9.27 & 7.71 & 6.94 & $496 \cdot 14$ \\
$\mathrm{La}_{28.9} \mathrm{Ni}_{67.5} \mathrm{Si}_{3.6}-\mathrm{H}$ & 9.33 & 7.74 & 6.98 & 504.06 \\
\hline
\end{tabular}




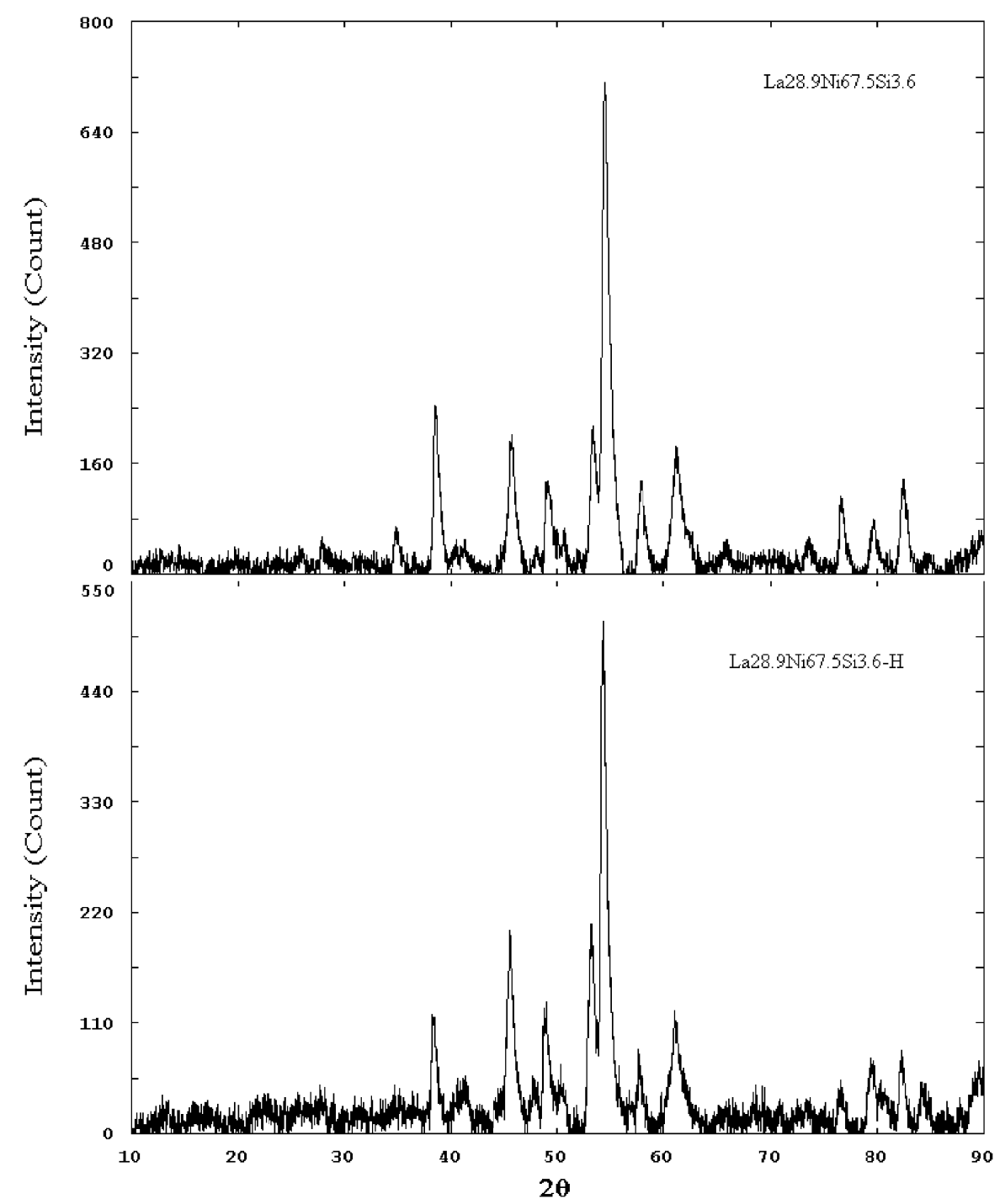

Figure 1. XRD patterns of $\mathrm{La}_{28.9} \mathrm{Ni}_{67.5} \mathrm{Si}_{3.6}$ and $\mathrm{La}_{28.9} \mathrm{Ni}_{67.5} \mathrm{Si}_{3.6}-\mathrm{H}$.

of impurities in the material. It takes about $100 \mathrm{~min}$ to absorb hydrogen, which is decreasing with increasing number of cycles. It takes only $10 \mathrm{~min}$ in 15 th cycle to absorb the same amount of hydrogen. After 15 cycles, the absorption time reaches to $2 \mathrm{~min}$. And now the material became activated and absorbs hydrogen within a few seconds as shown in figure 2(b).

\subsection{Resistance variation with hydrogen absorption}

Variation of resistance with $\mathrm{H} / \mathrm{M}$ is shown in figure 3 . It is clear that the resistance increases with hydrogen concentration. The increase in resistance with hydrogen concentration can be explained on the basis that hydrogen takes an electron from the conduction band of alloy and becomes hydrogen anion; therefore, the number of electrons in the conduction band decreases, so that the resistivity of the alloy increases.

\section{$3.4 P-C-T$ isotherm}

Hydrogen absorption isotherms of the alloy, $\mathrm{La}_{28.9} \mathrm{Ni}_{67.5}$ $\mathrm{Si}_{3.6}$, in the pressure range, $0.5 \leq P \leq 10$ bar and in the temperature range, $303 \leq T \quad 333 \mathrm{~K}$, are shown in figure 4. The maximum hydrogen intake capacity is found to be $2.4 \mathrm{wt} \%$ at 5.5 bar and $303 \mathrm{~K}$. These $\mathrm{P}-\mathrm{C}$ isotherms indicate two single $\alpha$ and $\beta$ regions and one mixed $\alpha+\beta$ phase region in the temperature and pressure range. The different phases and the effect of temperature on the general features of $\mathrm{P}-\mathrm{C}$ isotherm are shown in figure 4 . The increase of isotherm temperature from $303 \mathrm{~K}$ to $333 \mathrm{~K}$ causes the plateau pressure to increase from 2 bar to 3.8 bar and reduces width of the plateau which represents the miscibility regime of the $\alpha$ and $\beta$ phases. This process of narrowing of the plateau with increase of temperature continues until eventually at a certain critical temperature, $T_{\mathrm{c}}=333 \mathrm{~K}$, in figure, the plateau vanishes totally, reducing the miscibility 
(a)

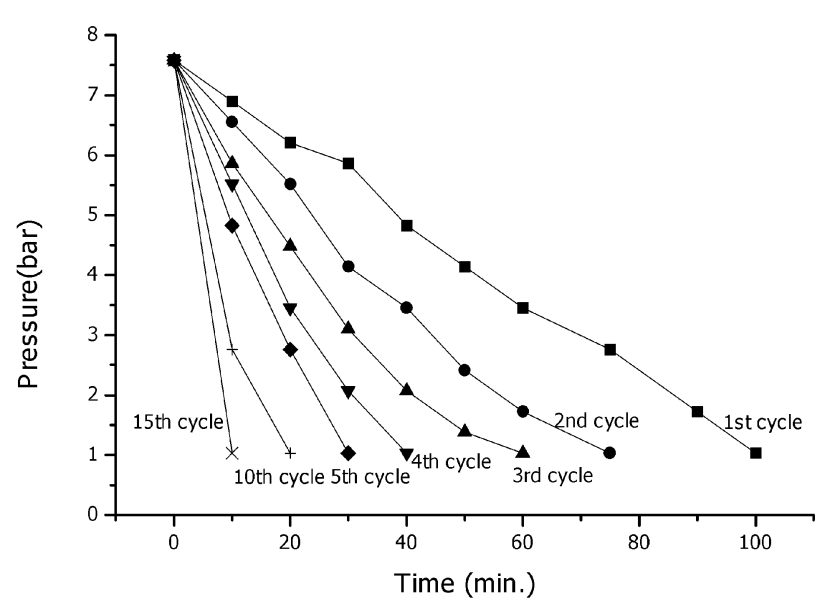

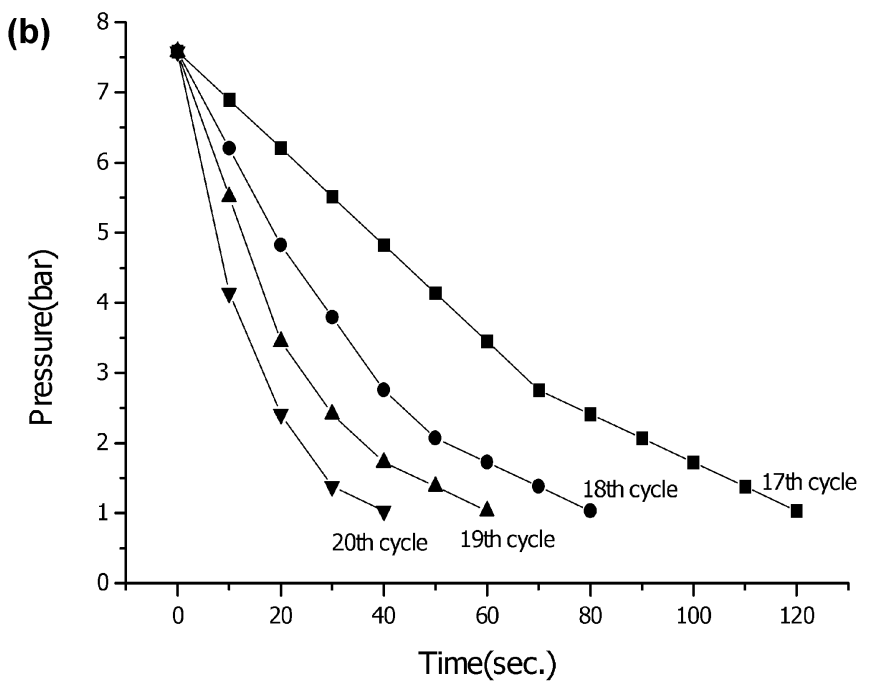

Figure 2. Variation of pressure with time: (a) during 1st few activation cycles and (b) after activation of material.

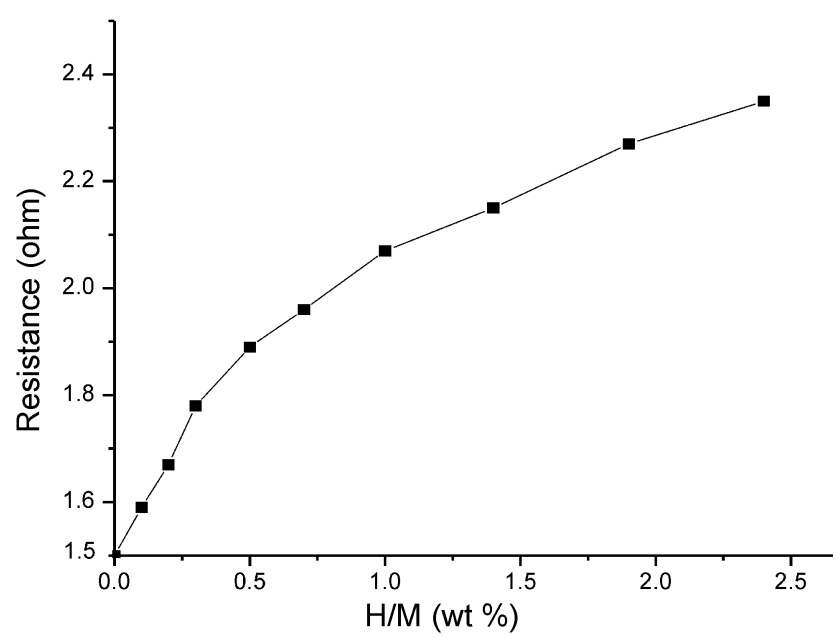

Figure 3. Variation of resistance with hydrogen concentration.

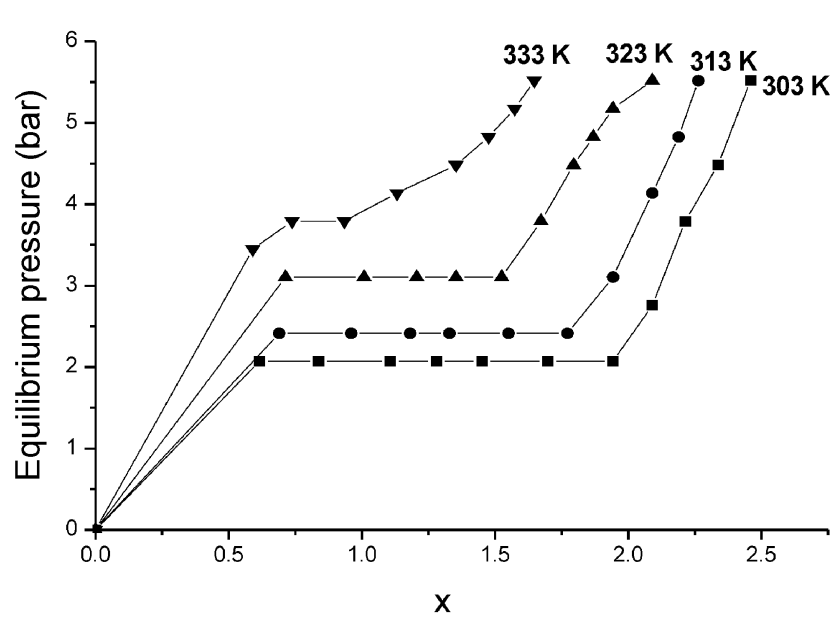

Figure 4. $\mathrm{P}-\mathrm{C}-\mathrm{T}$ isotherm for a range of temperatures.

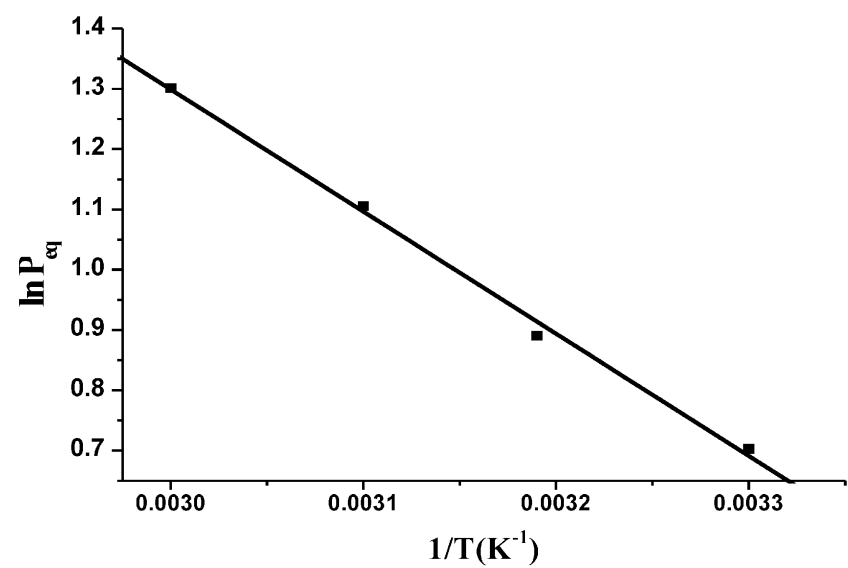

Figure 5. Typical Van't Hoff plot.

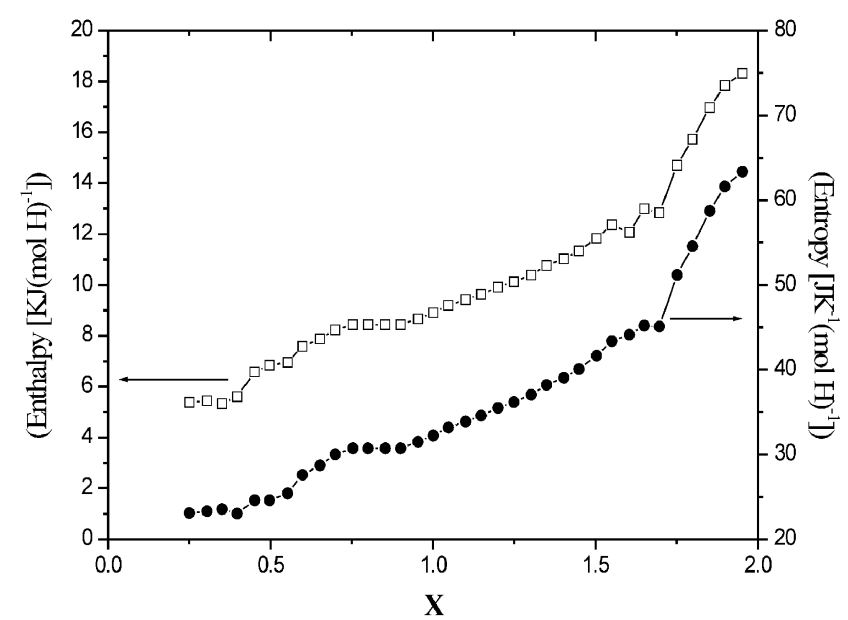

Figure 6. Variation of $\Delta H$ and $\Delta S$ with hydrogen concentration. 
Table 2. Effect of hydrogen on thermal properties of $\mathrm{La}-\mathrm{Ni}-$ Si alloy.

\begin{tabular}{lccc}
\hline System & $\begin{array}{c}\text { Thermal } \\
\text { conductivity } \\
(\mathrm{W} / \mathrm{mK})\end{array}$ & $\begin{array}{c}\text { Thermal } \\
\text { diffusivity } \\
\left(\mathrm{mm}^{2} / \mathrm{S}\right)\end{array}$ & $\begin{array}{c}\text { Specific } \\
\text { heat } \\
\left(\mathrm{MJ} / \mathrm{m}^{3} \mathrm{~K}\right)\end{array}$ \\
\hline $\mathrm{La}_{28.9} \mathrm{Ni}_{67.5} \mathrm{Si}_{3.6}$ & 0.997 & 0.425 & $2 \cdot 349$ \\
$\mathrm{La}_{28.9} \mathrm{Ni}_{67.5} \mathrm{Si}_{3.6}-\mathrm{H}$ & 0.925 & 0.239 & 3.892 \\
\hline
\end{tabular}

of the two phases to zero, and $\alpha$ phase converts continuously into the $\beta$ phase.

\subsection{Entropy and enthalpy variation of alloy}

The thermodynamics of metal hydrides has been discussed in detail by some workers (Oates and Flanagen 1981; Luo and Flanagen 1994). The enthalpy, $\ddot{A} H$, and entropy, $\ddot{A} S$, of hydride formation have been derived by utilizing Van't Hoff plot of $\ln P_{\text {eq }}$ vs $1 / T$, according to the equation

$$
R T \ln P_{\text {eq }}=2(\ddot{\mathrm{A}} H-T \ddot{\mathrm{A}} S),
$$

where $R$ is the ideal gas constant, $T$ the thermodynamic temperature, $P_{\text {eq }}$ the equilibrium pressure. The Van't Hoff plot for plateau region is shown in figure 5 . The parameters, entropy and enthalpy, were obtained using the least square technique from the slope and Y intercept of Van't Hoff plot shown in figure 5 for equilibrium pressure. The variation of enthalpy and entropy with hydrogen concentration is obtained by drawing such Van't Hoff plots for different hydrogen concentrations from the $\mathrm{P}-\mathrm{C}$ isotherm and the results are depicted in figure 6 . Since the heat of formation of the alloy hydrogen system is different for single and two phase regions, its variation with hydrogen concentration gives different slopes for different phase regions in the system. The practical significance of $\ddot{\mathrm{A}} H$ is that it is an index of thermochemical stability of metal hydride, low dissociation pressure and the requirement of moderately higher temperature to decompose it to liberate the hydrogen than hydride formation temperature (Viswanathan et al 1998). The heat of formation of $\mathrm{LaNi}_{5}$ has been found to be $7.6 \mathrm{kcal} / \mathrm{mol} \mathrm{H}_{2}$ (Wiswall 1978), while in our alloy it is found to be $8.44 \mathrm{kcal} / \mathrm{mol}$.

\subsection{Thermal conductivity, diffusivity and specific heat}

Simultaneous measurements of thermal conductivity and thermal diffusivity of pellets $\left(12 \mathrm{~mm}\right.$ dia) of $\mathrm{La}_{28.9} \mathrm{Ni}_{67.5}$ $\mathrm{Si}_{3.6}$ and $\mathrm{La}_{28.9} \mathrm{Ni}_{67.5} \mathrm{Si}_{3.6}-\mathrm{H}$ compacted under a load of 10 tons at room temperature have been made using TPS technique. The values of conductivity $(\lambda)$, diffusivity $(\chi)$ and specific heat are given in table 2 . The accuracy of measurements is within $2 \%$ in case of thermal conductivity and within $5 \%$ in case of thermal diffusivity. The variation in the value of conductivity of unhydrogenated and hydrogen- ated material is due to the grain sizes of material, because the coarse grained material has a lower thermal resistivity than a fine-grained one (Mebed 1983). After hydrogenation the sample breaks up into fine powder and the porosity of sample increased which in turn decreased the conductivity of powder. This is due to the presence of increased void space around the particles, which inhibits conduction by phonons (Kanan Bala et al 1989). It is observed that thermal diffusivity follows similar behaviour as thermal conductivity.

It has been noticed that the thermal conductivity of the sample decreases after hydrogenation which in turn will be responsible for increasing the capacity of holding the heat energy in the system. Also with the adsorption of hydrogen in the $\mathrm{La}-\mathrm{Ni}-\mathrm{Si}$ alloy, the degree of freedom for translational and rotatory motion will also increase. This gives rise to higher values of specific heat of the sample after hydrogenation.

\section{Conclusions}

The combination of structural, thermodynamical and thermal studies provide a good description of hydrogen absorption phenomena in the alloy. The lattice volume was found to increase with hydrogen absorption without structural transformation. The hydrogen absorption isotherms show that the present alloy is a good hydrogen storage material with low plateau pressure. Through the variation of $\Delta H$ and $\Delta S$ with $X$, the different phases are identified. It was also found that it makes more stable hydride in comparison with $\mathrm{LaNi}_{5}$. TPS study revealed reduction in thermal conductivity on hydrogenation.

\section{Acknowledgements}

This work was supported by a grant from UGC. The authors are grateful to Mr G Balachandra, DMRL, Hyderabad, for supplying the alloy. Thanks are due to Mr M P Sharma and Mr Manoj Kumar, Department of Physics, University of Rajasthan, Jaipur, for providing XRD technique. The assistance of Prof. N S Saxena in providing the TPS facility and in useful discussions is gratefully acknowledged.

\section{References}

Ahn H J and Lee J Y 1991 Int. J. Hydrogen Energy 293

Berznitsky M and Jacob I 2003 J. Alloys and Compounds 351 180

Bououdina A M and Guo Z X 2000 Mater. Technol. 15269

Devi Babita, Banthia A S and Jain I P 2004 Int. J. Hydrogen Energy 291289

Gustaffson S E 1991 Rev. Sci. Instrum. 62797

Hector L G Jr, Herbst J F and Capehart T W 2003 J. Alloys and Compounds $\mathbf{3 5 3} 74$

Jacob I and Berznitsky M 2002 J. Alloys and Compounds 3361 
Jain I P, Vijay Y K and AbuDaka M I S 2002 Int. J. Hydrogen Energy 2785

Josephy Y, Bershadsky E and Ron M 1991 J. Less Common Metals 172997

Kanan Bala, Pradhan P R, Saxena N S and Saksena M P 1989 J. Phys. D: Appl. Phys. 221068

Latroche M, Joubert J M and Notten P H L 1999 J. Solid State Chem. 146313

Luo W and Flanagen T B 1994 J. Phase Equilibria 1520

Mebed M M 1983 High Temperature High Pressure 15113

Nakamura Y, Bowman R C and Akiba E 2004 J. Alloys and Compounds $\mathbf{3 7 3} 183$

Notten P H L and Latroche M 1999 J. Electrochem. Soc. 1463181

Oates W A and Flanagen T B 1981 Proc. Solid State Chem. 13193

Sato A and Yartys V A 2004 J. Alloys and Compounds 373161

Schlapbach L (ed.) 1988 Hydrogen in intermetallic compounds I/II. Topics in applied physics (Berlin: Springer-Verlag) p. 63
Schlapbach L (ed.) 1992 Hydrogen in intermetallic compounds I/II. Topics in applied physics (Berlin: Springer Verlag) p. 67

Seo C Y, Choi S J, Choi J, Park C N and Lee J Y 2003 J. Alloys and Compounds $\mathbf{3 5 1} 255$

Singh K, Saxena N S and Maharajan N B 2002 Phys. Status Solidi (a)189 197

Sivakumar R, Ramprabhu S, Ramarao K V, Mayer B and Schmidt P C 2000 J. Alloys and Compounds 302146

Viswanathan B, Sastry M V C and Murthy S S (eds) 1998 Metal hydrides (New Delhi: Narosa Publishing Company)

Wipf H (ed.) 1997 Hydrogen in metals III. Topics in applied physics (Berlin: Springer) Vol. $\mathbf{7 3}$

Wiswall R 1978 Hydrogen storage in metals (eds) G Alefeld and J Volkl (Berlin: Springer Verlag) Ch. 5

Yamaguchi M and Akiba E 1994 Ternary alloys in material science and technology (eds) R W Cahn et al (Weinheim, Germany: VCH, Verlagessellschaff), Vol. 3B 